(3.4\%), and family physicians, $49(20.8 \%)$. FM was considered a clinical diagnosis by $208(88.1 \%)$ and most physicians think FM is both a physical and psychological condition, 190 (80.5\%). Full results on physicians' perceptions is shown in Table 1. Fatigue was the symptom which most physicians agreed or strongly agreed was important in FM, 219 (92.7\%). Disagreement (any degree) was greater regarding abdominal pain/cramping being an important symptom in FM, 52 (22\%). Complete results can be seen in Image 1.

Table 1. Perceptions' of physicians about FM.

\begin{tabular}{lc}
\hline \multicolumn{1}{c}{ Variable } & \\
\hline $\mathrm{FM}$ is a clinic diagnostic, $\mathrm{n}(\%)$ & $208(88.1)$ \\
Unsure $\mathrm{FM}$ is a clinical diagnostic, $\mathrm{n}(\%)$ & $12(5)$ \\
$\mathrm{FM}$ is a physical illness, $\mathrm{n}(\%)$ & $33(14)$ \\
$\mathrm{FM}$ is a psychological illness, $\mathrm{n}(\%)$ & $11(4.7)$ \\
$\mathrm{FM}$ is both physical and psychological, $\mathrm{n}(\%)$ & $190(80.5)$ \\
$\mathrm{FM}$ has a negative impact on quality of life, $\mathrm{n}(\%)$ & $227(96.2)$ \\
FM has a negative impact on life expectancy, $\mathrm{n}(\%)$ & $135(57.2)$
\end{tabular}

Conclusion: FM was considered a clinical diagnostic and an illness both physical and psychological by most physicians. Headache and abdominal pain/cramping are symptoms less likely to be perceived as important in patients with FM. References:

[1] Perrot S, Choy E, Petersel D, et al. Survey of physician experiences and perceptions about the diagnosis and treatment of fibromyalgia. BMC Health Serv Res. 2012 Oct 10;12:356.

[2] Kianmehr N, Haghighi A, Bidari A. Are general practitioners well informed about fibromyalgia? Int J Rheum Dis. 2017 Dec;20(12):1917-1921

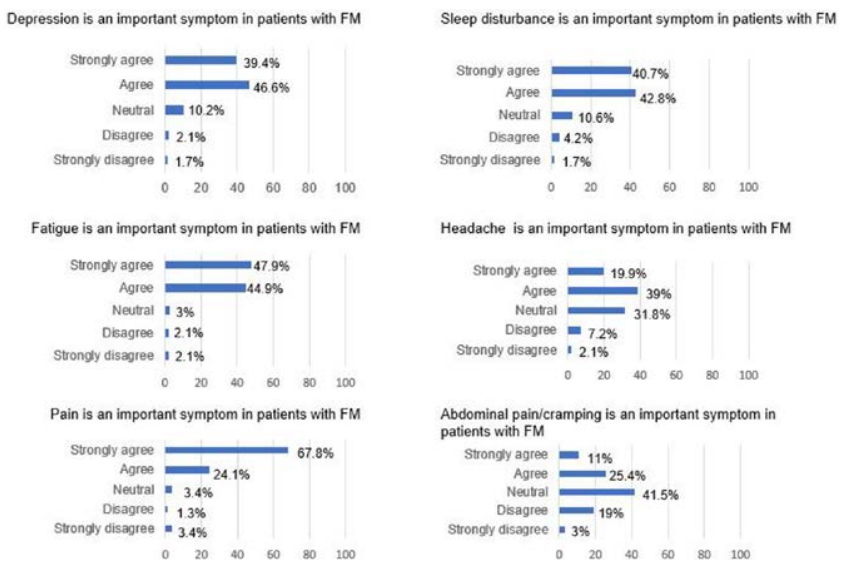

Figure 1. Image 1. Perception of accompanying symptoms of fibromyalgia (FM)

Disclosure of Interests: None declared

DOI: 10.1136/annrheumdis-2020-eular.4845

\section{AB1360-HPR A MODEL TO IMPROVE MINORITY PATIENT RECRUITMENT IN LUPUS CLINICAL TRIALS - THE AMERICAN COLLEGE OF RHEUMATOLOGY MIMICT PROJECT EXPERIENCE}

S. Sheikh ${ }^{1}$, N. Wanty ${ }^{2}$, S. Mccalla ${ }^{3}$, A. Santana ${ }^{1}$, S. Saxena Beem ${ }^{1}$, J. Walker ${ }^{1}$, D. Holt ${ }^{4}$, A. Howell ${ }^{4}$, K. Holtz ${ }^{2}$, S. Williams ${ }^{3}$, A. Anandarajah ${ }^{4}{ }^{1}$ University of North Carolina, Chapel Hill, United States of America; ${ }^{2} \mathrm{KDH}$ Research \& Communication, Atlanta, United States of America; ${ }^{3}$ American College of Rheumatology, Atlanta, United States of America; ${ }^{4}$ University of Rochester, Rochester, United States of America

Background: In the US, African Americans and Latinos are underrepresented in lupus clinical trials (LCTs), ${ }^{1}$ despite experiencing the greatest lupus disease burden. ${ }^{2,3}$ Low participation in LCTs results in inadequate data on treatment effectiveness for minority patients, and fewer opportunities for better care and treatment options. ${ }^{1}$ Only one percent of minority patients are referred to clinical trials each year. ${ }^{4}$ Provider barriers to making referrals include limited time and unfamiliarity with lupus and LCT opportunities. ${ }^{4}$ Using US fedral grant funds, the American College of Rheumatology (ACR) developed MIMICT, a two-part model with associated materials to address provider-side LCT referral barriers. The materials include a toolkit for clinical trial sites and an educational toolkit for providers.

Objectives: Our objectives are to:

-Describe the US LCTs disparities.

-Discuss the research methodology to evaluate the two-part MIMICT model.
-Assess the feasibility of the model to increase minority involvement in clinical trials.

Methods: We designed two studies to evaluate the MIMICT model.The first study used an online, pretest/posttest, two-group evaluation approach to assess the extent to which the educational toolkit increased providers' knowledge, attitudes, self-efficacy, and behavioral intentions to refer minority patients to clinical trial. We conducted the study in 2018 with primary care providers (PCPs) and again in 2019/2020 with speciality providers. The second study used a longitudinal, mised methods, case-study approach to explore the real-world use of the toolkits with clinical trial site teams at two university medical centers.

Results: In the first study,among MIMCT-exposed PCPs, mean scores indicated statistical significance at $\mathrm{p} \leq 0.001$ with more knowledge about referring [55.84 ( $\mathrm{sd}=23.51)$ vs $41.76(s d=19.98)$ ], more self-efficacy to refer [55.00 (sd=37.22) vs. 37.99 (sd=34.42)] and more intentions to refer [61.36 (43.85) vs. 33.41 (41.16)] African American patients to LCTs among the treatment group than the control group, respectively. This presentation will discuss additional data comparing the study in 2018 and the study in 2019/2020 and look comparatively at outcomes across provider type.

In the second study, we found that the driver for successful engagemetn of providers and their subsequent use of the educational toolkit was the development of a trusting relationship between the clinical trial site teams and providers in the community. The development of trust took repeated and varied modes of contact, which we will discuss in-depth.

Conclusion: The MIMICT educational toolkit increase knowledge, self-efficacy, and intentions to refer lupus patients to LCTs. However, building trust between LCT sites and local providers takes time and repeated outreach, but the potential benefits to medicine and minority health are substantial.

References:

[1] The Society for Women's Health Research. (2011). Dialogues on diversifying clinical trials: successful strategies for engaging women and minorities in clinical trials. Washington, DC: Food and Drug Administration, Office of Women's Health.

[2] Falasinnu, T., Chaichian, Y., Bass, M. B., \& Simard, J. F. (2018). The representation of gender and race/ethnic groups in randomized clinical trials of individuals with sytemic lupus erythematosus. Current Rheumatology Reports, 20(4)

[3] Pons-Estel, G. J., Alarcon, G. S., Scofield, L., Reinlib, L., \& Cooper, G. S (2010). Understanding the epidemiological progression of systemic lupus erythematosus. Seminars in Arthritis and Rheumatism, 39(4).

[4] Korieth, K. (2016). Engaging healthcare providers as research facilitators. The CenterWatch Monthly, 23, 1-5.

Disclosure of Interests: None declared

DOI: 10.1136/annrheumdis-2020-eular.654

\section{HPR Interdisciplinary research}

\section{AB1361-HPR PRIMARY CARE PHARMACOLOGICAL TREATMENT FOR PATIENTS WITH HAND ARTHRALGIA}

M. M. Castañeda-Martínez ${ }^{1}$, G. Figueroa-Parra ${ }^{1}$, D. Vega-Morales ${ }^{1}$, J. M. Calderón Espinosa ${ }^{1}$, B. R. Vázquez Fuentes ${ }^{1}$, J. A. Esquivel Valerio ${ }^{1}$, Y. G. Ordoñez Azuara ${ }^{2}$, D. Á. Galarza-Delgado'. 'University Hospital "Dr. José Eleuterio González", Rheumatology Service, Monterrey, Mexico; ${ }^{2}$ University Hospital "Dr. José Eleuterio González", Family Medicine Service, Monterrey, Mexico

Background: Primary care physicians (PCP) are the first point of contact for patients with a new-onset inflammatory rheumatic disease, like rheumatoid arthritis (RA). Consequently, primary care is crucial to the early diagnosis and prompt treatment of such individuals. The first three months following the onset of RA symptoms represent an important therapeutic window. Historically, patients with inflammatory arthritis received first-line treatment with non-steroidal anti-inflammatory drugs (NSAIDs), moving to synthetic disease-modifying anti-rheumatic drugs (DMARDs) relatively late in the disease process. As synthetic DMARDs are usually initiated in secondary care by rheumatologists, PCP focus on alleviation of patient's discomfort. Documented problems in primary care practice include accuracy of diagnosis, test ordering, medication use and delays in referral.

There is no evidence of which is the pharmacological treatment more commonly used for hand arthralgia in Family Medicine patients of a university hospital on their first or second visit.

Objectives: To examine the primary care physicians' pharmacological treatment prescribed for hand arthralgia in a Family Medicine Consultation.

Methods: In a period of a year and two months, eligible patients were recruited on their first or second visit to the Family Medicine Consultation of the Hospital Universitario "Dr. José Eleuterio González" in Monterrey, Nuevo León, México. Eligible patients were adults (aged $\geq 18$ years) with hand arthralgia as their chief complaint, who had not rheumatologic diagnosis and wasn't caused by trauma. Ninety patients were recruited, data were collected by capturing the prescription made by PCP. 
Results: In this cohort of 90 patients, 71 (78.9\%) were women. Of the 90 patients, $19(21.1 \%)$ had no pharmacological prescription at all. Forty-nine patients $(54.4 \%)$ had one prescribed drug, $17(18.9 \%)$ had two drugs and $5(5.6 \%)$ had three drugs. Prescribed drugs and their frequencies are reported in Table 1.

Table 1. Prescribed drugs and frequencies.

\begin{tabular}{lc}
\hline \multicolumn{1}{c}{ Drug } & $\mathbf{n}(\%)$ \\
\hline No treatment & $19(21.1)$ \\
Celecoxib & $26(28.9)$ \\
Oxicams & $22(24.4)$ \\
Propionic acid derivatives & $6(6.7)$ \\
Phenyl Acetic acids & $5(5.6)$ \\
Acetaminophen & $15(16.7)$ \\
Tramadol & $12(13.3)$ \\
Steroids & $11(12.2)$ \\
Methotrexate & $1(1.1)$ \\
\hline
\end{tabular}

Conclusion: The most common group of drugs used for hand arthralgia in this cohort of patients was NSAID, and the most used of this group was celecoxib. Only in one patient, PCP prescribed disease-modifying anti-rheumatic drugs (DMARD) therapy, in this case was methotrexate. Almost $80 \%$ of the patients were prescribed with at least one drug without knowing the final diagnosis.

References:

[1] Warburton L, Hider SL, Mallen CD, Scott IC. Suspected very early inflammatory rheumatic diseases in primary care. Best Pract Res Clin Rheumatol. 2019;33(4):101419

[2] Calabrese L. Rheumatoid arthritis and primary care: The case for early diagnosis and treatment. The Journal of the American Osteopathic Association. 1999;99(6):313.

Disclosure of Interests: None declared

DOI: 10.1136/annrheumdis-2020-eular.4728

\section{AB1362-HPR COMMON PRACTICE IN DELIVERY OF INTRA- ARTICULAR THERAPIES IN RMDS BY HEALTH PROFESSIONALS: RESULTS FROM A EUROPEAN SURVEY}

J. De la Torre-Aboki ${ }^{1}$, I. Pitsillidou ${ }^{2}$, J. Uson Jaeger ${ }^{3}$, E. Naredo ${ }^{4}$, L. Terslev ${ }^{5}$, M. Boesen ${ }^{6}$, H. Pandit', I. Möller ${ }^{8}$, M. A. D'agostino ${ }^{9}$, W. U. Kampen ${ }^{10}$, T. O'neill ${ }^{11}$ M. Doherty ${ }^{12}$, F. Berenbaum ${ }^{13}$, V. Vardanyan ${ }^{14}$, E. Nikiphorou ${ }^{15}$, S. C. RodriguezGarcía $^{16}$, R. Castellanos-Moreira ${ }^{17}$, L. Carmona ${ }^{18} .{ }^{1}$ Hospital General Universitari d'Alacant, Alacant, Spain; ${ }^{2}$ Cyprus League Against Rheumatism, Nicosia, Cyprus; ${ }^{3}$ Hospital Universitario de Móstoles, Móstoles, Spain; ${ }^{4}$ Hospital Universitario Fundación Jiménez Díaz, Madrid, Spain; ${ }^{5}$ Rigshospitalet, København, Denmark; ${ }^{6}$ Bispebjerg and Frederiksberg Hospital, København, Denmark; ${ }^{7}$ University of Leeds, Leeds, United Kingdom; ${ }^{8}$ Institut Poal de Reumatologia, Barcelona, Spain; ${ }^{9}$ APHP-Université Paris-Saclay Versailles, Inserm, Boulogne-Billancourt, France; ${ }^{10}$ Rad. Allianz, Nuklearmedizin Spitalerhof, Hamburg, Germany; ${ }^{11}$ University of Manchester, Manchester, United Kingdom; ${ }^{12}$ University of Nottingham, Nottingham, United Kingdom; ${ }^{13} \mathrm{AP}$-HP Sorbonne Université, Inserm, Paris, France; ${ }^{14}$ Mikayelyan University Hospital, Yerevan, Armenia; ${ }^{15}$ King's College, London, United Kingdom;

${ }^{16}$ Hospital de La Princesa, Madrid, Spain; ${ }^{17}$ Hospital Clínic de Barcelona,

Barcelona, Spain; ${ }^{18}$ InMusc, Madrid, Spain

Background: Intra-articular therapies (IAT) are routinely used in rheumatic and musculoskeletal diseases (RMDs); however large variability exists regarding current practice of delivery amongst health professionals.

Objectives: To inquire about common practice aspects to inform the EULAR Taskforce for the IAT of arthropathies.

Methods: A steering committee prepared a 160 -item questionnaire based on the information needs of the Taskforce. The survey was disseminated via EULAR professional associations and social media and it was open to any health professional treating persons with RMDs, regardless of using IAT personally.

Results: The survey was answered by 186 health professionals from 26 countries, the large majority of whom $(77 \%)$ were rheumatologists, followed by nurses $(12 \%)$, general practitioners $(2 \%)$ and orthopaedic surgeons $(2 \%)$. The two collectives that perform IAT routinely are rheumatologists $(97 \%)$ and orthopaedic surgeons $(89 \%)$, with other professionals $<50 \%$. Specific training was compulsory for $32 \%$. The most frequent indication for IAT is inflammatory arthritis $(76 \%)$, followed by osteoarthritis $(74 \%)$, crystal arthritis $(71 \%)$ and bursitis $(70 \%)$; and all joints are injected, with knee $(78 \%)$ and shoulder $(70 \%)$ being the most frequent. When questioned about specific contexts, such as pre-surgical, diabetic or hypertensive patients, variability among respondents was evident, with around 30 to $69 \%$ of professionals considering it acceptable to inject glucocorticoids (GC), while in others there was less variability (prosthetic or septic joints, $<1 \%$ ). GCs are the most used compounds, followed by hyaluronic acid and saline/dry puncture. Only $66(36 \%)$ use ultrasound to guide IAT. In their opinion, to be accurately in the joint is moderately to largely important for large joints (80\%) and very important in small joints. The maximum number of injections to perform safely in the same joint within one year was " 2 to 3 " for $65 \%$ ( $2 \%$ thought there is "No limit"). The majority reported that they informed patients about side-effects $(73 \%)$, benefits $(72 \%)$, and the nature of the procedure $(72 \%)$, and less frequently about other aspects; with $10 \%$ obtaining written consent and $56 \%$ oral consent (mandatory only for $32 \%$ ). Other questions help to understand the setting and procedures followed, including use of local anaesthetics and care after injection. Conclusion: Although often performed in clinical practice for RMDs, there is apparent variability in several elements related to delivery of this treatment. This information, together with patient input, will help design current recommendations where research evidence is not available.

Acknowledgments: Eular Taskforce grant CL109

Disclosure of Interests: Jenny de la Torre-Aboki: None declared, IRENE Pitsillidou: None declared, Jacqueline Uson Jaeger: None declared, Esperanza Naredo: None declared, Lene Terslev: None declared, Mikael Boesen Consultant of: AbbVie, AstraZeneca, Eli Lilly, Esaote, Glenmark, Novartis, Pfizer, UCB, Paid instructor for: IAG Image Analysis Group, AbbVie, Eli Lilly, AstraZeneca, esaote, Glenmark, Novartis, Pfizer, UCB (scientific advisor)., Speakers bureau: Eli Lilly, Esaote, Novartis, Pfizer, UCB, Hemant Pandit Grant/research support from: Glaxo Smith Kline (GSK) for work on Diclofenac Gel, Speakers bureau: Bristol Myers Squibb for teaching their employees about hip and knee replacement, Ingrid Möller: None declared, Maria Antonietta D'Agostino Consultant of: AbbVie, BMS, Novartis, and Roche, Speakers bureau: AbbVie, BMS, Novartis, and Roche, Willm Uwe Kampen: None declared, Terence O'Neill: None declared, Michael Doherty Grant/research support from: AstraZeneca funded the Nottingham Sons of Gout study, Consultant of: Advisory borads on gout for Grunenthal and Mallinckrodt, Francis Berenbaum Grant/research support from: TRB Chemedica (through institution), MSD (through institution), Pfizer (through institution), Consultant of: Novartis, MSD, Pfizer, Lilly, UCB, Abbvie, Roche, Servier, Sanofi-Aventis, Flexion Therapeutics, Expanscience, GSK, Biogen, Nordic, Sandoz, Regeneron, Gilead, Bone Therapeutics, Regulaxis, Peptinov, 4P Pharma, Paid instructor for: Sandoz, Speakers bureau: Novartis, MSD, Pfizer, Lilly, UCB, Abbvie, Roche, Servier, Sanofi-Aventis, Flexion Therapeutics, Expanscience, GSK, Biogen, Nordic, Sandoz, Regeneron, Gilead, Sandoz, Valentina Vardanyan: None declared, Elena Nikiphorou: None declared, Sebastian C Rodriguez-García Speakers bureau Novartis Farmaceutica, S.A., Merck Sharp \& Dohme España, S.A., Sanofi Aventis, UCB Pharma, Raul Castellanos-Moreira: None declared, Loreto Carmona Grant research support from: Novartis Farmaceutica, SA, Pfizer, S.L.U., Merck Sharp \& Dohme España, S.A., Roche Farma, S.A, Sanofi Aventis, AbbVie Spain, S.L.U., and Laboratorios Gebro Pharma, SA (All trhough institution)

DOI: 10.1136/annrheumdis-2020-eular.96

\section{AB1363-HPR EVALUATION OF SELECTION CRITERIA OF CLINICIANS IN THE TREATMENT OF OSTEOPOROSIS, OSTREQ RESEARCH IN TURKEY}

\section{E. G. Kahraman ${ }^{1}$, S. Akar ${ }^{1}$, B. Ö. Pamuk' ${ }^{1}{ }^{1}$ Izmir Katip Çelebi Üniversitesi} Atatürk Eğitim ve Araştırma Hastanesi, Izmir, Turkey

Background: Osteoporosis is a disease with increasing prevalence in the aging and growing world population and its insidious progression and lack of findings without fracture cause certain difficulties in the diagnosis and treatment of this disease. There are many medical and paramedical treatment options for osteoporosis, and clinicians make these treatment decisions with many factors in mind. Objectives: We wanted to evaluate the importance of these factors for clinicians through a questionnaire. This 17-question questionnaire aimed to investigate the factors that clinicians consider in the planning of osteoporosis treatment and the effect of these factors on treatment planning. We made the Turkish version of the OSTEQ questionnaire in this study which factors clinicians in planning treatment for osteoporosis in Turkey we aimed to investigate that take into consideration.

Methods: OSTREQ questionnaire developed by Makraz et al. are used in this research. In this survey, which consists of 8 sections (health care system, patients' preferences regarding regimen's administration, usage, cost, severity of disease, treatment efficacy, safety profile and pharmaceutical industry) and 17 questions, the participants were asked to evaluate their answers with 5 different scales: Absolutely Preventive, Partially Preventive, Neither Preventive or Encouraging, Partially Encouraging, Absolutely Encouraging.

Clinicians of Rheumatology, Physical Therapy and Rehabilitation, Endocrinology and Metabolic Diseases participated in our study. The questionnaires were filled in by e-mail or by inviting the participants to the our university or by going to the clinics where the clinicians were working

Results: In our study 37 (21.8\%) were endocrinology, 49 (28.8\%) were rheumatology and $84(49.4 \%)$ were physical therapy and rehabilitation specialists. The overall Cronbach alpha coefficient of the questionnaire was found to be 0.855 . No material was found to significantly increase the internal reliability coefficient if deleted. As a result of $t$-test in $27 \%$ lower and upper groups to measure the discriminative powe of the items, it was seen that all items made a significant difference in the lowe and upper groups, which were formed according to the total score of 27 people. Confirmatory factor analysis and internal reliability results did not require removal of 